\title{
O professor coordenador pedagógico e a fragilidade da carreira docente ${ }^{1}$ MARIA JOSÉ DA SILVA FERNANDES*
}

\section{RESUMO}

Este artigo tem o objetivo de apresentar os resultados de uma pesquisa que analisou a criação da função de professor coordenador pedagógico (PCP) nas escolas estaduais de São Paulo no bojo das reformas educacionais ocorridas em meados dos anos 90 . Norteados por uma pesquisa de caráter bibliográfico-documental que analisou documentos da Secretaria de Educação (inclusive legislação), materiais produzidos por entidades representativas dos professores e uma bibliografia relacionada à história da educação, procuramos elucidar a trajetória percorrida pela coordenação pedagógica em diferentes contextos históricos, analisando a concepção de trabalho docente em relação a esses momentos. Por outro lado, investigamos as dificuldades de trabalho do PCP nas escolas da rede estadual de ensino, recorrendo a pesquisas que foram produzidas sobre o tema, cuja análise nos permitiu a aproximação com o contexto de trabalho da função e o reconhecimento das implicações das reformas educacionais para a constituição da profissionalidade docente.

Palavras-chave: Coordenação pedagógica, Reforma do ensino, Profissionalização, Professores.

\section{RESUMEN}

Este artículo tiene el objetivo de presentar los resultados de una investigación que analizó la creación de la función de profesor coordinador pedagógico (PCP) en las escuelas dependientes del gobierno del Estado de San Pablo y como parte central de las reformas educativas implementadas a mediados de los años 90. Orientados por una investigación de carácter bibliográfico que analizó documentos de la Secretaría de Educación (inclusive la legislación), materiales producidos por instituciones representativas de los profesores y una bibliografía sobre historia de la educación, intentamos dilucidar la trayectoria de la coordinación pedagógica en diferentes contextos históricos, analizando la concepción del trabajo docente en relación con esos momentos. Por otro lado, investigamos las dificultades de trabajo del PCP en las escuelas del sistema de enseñanza dependiente del gobierno del Estado de San Pablo. Recurrimos para esto a investigaciones ya realizadas sobre el tema, cuyo análisis nos permitió aproximarnos al contexto de trabajo de esta función e identificar las implicancias de las reformas educativas para la constitución del profesionalismo docente

Palabras clave: Coordinación pedagógica, Reforma de la enseñanza, Profesionalización, Profesores.

\footnotetext{
ABSTRACT

${ }^{1}$ Este artigo derivou de trabalho apresentado, com algumas alterações, na $28^{\text {a }}$ Reunião Anual da Associação Nacional de Pós-Graduação e Pesquisa em Educação (ANPED).

* Professora Assistente Doutora do Departamento de Educação da Faculdade de Ciências da Universidade Estadual Paulista (Unesp)/Bauru.
} 
This article aims to present the results of a study that examined the development of the role of a pedagogical teacher-coordinator (PTC) in São Paulo's state schools amidst educational reforms in the mid-90s. Guided by a bibliographical survey that examined the documents of the Department of Education (including legislation), materials produced by organizations representing teachers and a bibliography related to the history of education, we seek to elucidate the trajectory of teaching coordination in different historical contexts, analyzing the conception of teaching in relation to these moments. Furthermore, we investigate the difficulties of PTC work in state schools, according to studies that have been produced on the subject, whose analysis allowed us to get a closer picture of the PTC working context and recognize the implications of educational reforms to the establishment of professional teaching.

Keywords: pedagogical coordination, educational improvement, professional teachers.

A educação pública paulista foi marcada nos anos finais do século XX por grandes transformações. O cotidiano escolar foi impactado por problemas de ordem macroestrutural que afetaram a microestrutura da sala de aula. A mudança de valores, o desemprego crescente, a fragilização da educação como mecanismo de ascensão social e a própria desvalorização do professor como sujeito que trabalha com o conhecimento provocaram situações de desconforto e desânimo, tanto nos alunos como nos professores.

Entre os fatores que alteraram o cotidiano escolar e que refletiram a interferência da macroestrutura na educação está a aplicação de políticas educacionais formatadas sob o modelo de grandes pacotes reformistas que transformaram o que ensinar, o como ensinar e a própria estrutura de gestão e organização das escolas públicas. De acordo com Oliveira (2003, p. 45), as reformas que foram implementadas nas escolas públicas nesse período estavam afinadas com as orientações globais para a educação, verificando-se forte relação entre a política educacional, a política econômica e o papel do Estado na democratização do ensino.

Nesta relação, as políticas governamentais passaram a ser regidas pela ordem do mercado, o que alterou as condições de trabalho e de profissionalidade docente, impondo inúmeros desafios às escolas e aos seus sujeitos, notadamente "o professor é, hoje, posto em xeque, principalmente por sua condição de fragilidade em trabalhar com os desafios da época" (Cunha, 1999, p. 127). Apesar da centralidade apresentada nos discursos reformistas, os professores continuaram a ser tratados pelas políticas públicas como objetos e continuaram a ser considerados executores das mudanças que os experts elaboram, sendo posteriormente responsabilizados pelos problemas apresentados na implementação das reformas no âmbito do contexto escolar, assumindo a culpa e o fracasso de algo que sequer puderam sugerir (Dias-da-Silva, 2002; Almeida, 2000; Sampaio, 2002; Marin; Guarnieri, 2002; Cunha, 1999). 
No impacto dessas reformas educacionais de cunho neoliberal, promovidas, em grande parte, com o financiamento de agências internacionais (Banco Mundial, BIRD), a educação pública paulista vivenciou, no final dos anos 90, a imposição de reformas que alteraram profundamente o cotidiano de suas escolas. A "Escola de Cara Nova", nome dado ao pacote inicial de reformas, promoveu alterações sem precedentes na rede pública de ensino, impondo aos professores mudanças, como a progressão continuada, a reorganização escolar, as salas-ambiente, a implantação de projetos, a flexibilização do ensino médio e outras. Entre as medidas que chegaram às unidades escolares, estava a implantação da função de professor coordenador pedagógico ${ }^{2}$ em todas as escolas públicas com mais de dez classes em funcionamento.

A expansão da função de PCP, para a quase totalidade das escolas da rede estadual de ensino, foi garantida no bojo das reformas educacionais pela Resolução SE n ${ }^{\circ} 28$, de 4 de abril de 1996, que dispôs sobre o processo de escolha de professor para exercício das funções de coordenação pedagógica. De acordo com essa resolução, a escolha dos professores seria feita por meio de um processo que envolveria a realização de uma prova escrita eliminatória elaborada pelas Diretorias de Ensino, apresentação de uma proposta de trabalho individualizada para cada unidade escolar, eleição pelos pares e ratificação da escolha pelo Conselho de Escola. Diante deste quadro, os professores e o Conselho de Escola passaram a ter a grande responsabilidade de escolher entre os pares aquele que ocuparia temporariamente a função de professor coordenador pedagógico $^{3}$.

A grande novidade desta resolução foi, além de garantir na prática aquilo que já se anunciava legalmente ${ }^{4}$, permitir que qualquer professor com mais de três anos de exercício no magistério paulista pudesse exercer a função de PCP, independentemente de sua formação inicial, o que o desobrigava tanto de ser formado em Pedagogia com habilitação em Supervisão Escolar quanto de acumular larga experiência profissional. Dessa forma, a Secretaria da Educação

\footnotetext{
${ }^{2}$ É necessário um esclarecimento sobre a coordenação pedagógica, uma vez que o Estado de São Paulo priorizou, no início da década de 70, a separação legal e técnica entre supervisão escolar, coordenação pedagógica e professor coordenador pedagógico, diferentemente de outros Estados brasileiros. O trabalho do supervisor é centrado em unidades de trabalho (Diretorias de Ensino) e no acompanhamento de um número variado de escolas, enquanto a coordenação pedagógica é um cargo previsto legalmente, mas praticamente extinto desde o final da década de 70. Já a função de professor coordenador pedagógico (PCP) é ocupada por professores eleitos entre os seus pares que realizam nas escolas o trabalho de coordenação e acompanhamento das ações pedagógicas.

3 A partir de 2006, a função passou a ser denominada apenas Professor Coordenador (PC). Com a Resolução $n^{\circ}$ 66/2006, foram alteradas também a forma de escolha dos candidatos e as atribuições destinadas ao cargo.

${ }^{4}$ A análise da legislação que rege as escolas estaduais nos permitiu verificar que nos Estatutos do Magistério da década de 70 (1974 e 1978) já havia a previsão legal para a função, embora até a década de 90 ela tivesse se efetivado apenas em experiências pontuais realizadas pela Secretaria Estadual de Educação.
} 
possibilitou aos professores sem habilitação específica e com alguma experiência profissional assumir a tarefa de coordenação pedagógica, ou seja, a função não seria ocupada por um expert da educação, por um especialista, mas por um par, um sujeito que deveria ocupar uma função que pressupunha a convivência constante com as dificuldades e os dilemas presentes no cotidiano dos professores da escola pública.

Durante a análise desse contexto de criação da função de PCP, algumas questões nos levaram a uma investigação mais ampla. Estaria a criação da função ligada especificamente aos momentos de reformas educacionais recentes? Em outros cenários políticos a função também se faria necessária? Por que a função, reivindicação histórica da categoria docente, foi incorporada ao pacote de reformas neoliberais? Qual a profissionalidade presente no trabalho do PCP? Com base nestas questões, passamos a trabalhar com a hipótese de que a função de professor coordenador pedagógico foi incorporada às reformas educacionais atuais mais como um mecanismo de controle do que como uma função de articulação do trabalho coletivo, essa sim uma bandeira progressista.

Partindo dessa hipótese, iniciamos uma análise bibliográfico-documental ${ }^{5}$ que nos revelou que a função de coordenação pedagógica esteve anteriormente relacionada a outros contextos educacionais, como foi o caso, na década de 60, dos Colégios Vocacionais, das Escolas de Aplicação e das Escolas Experimentais (Garcia, 1995; Fusari, 1997; Tamberlini, 2001; Silva Jr., 2002). Apesar de serem casos pontuais, essas experiências são consideradas um dos mais importantes projetos educacionais paulistas no século XX. Assim, a função nasceu junto com a inovação educacional, com a perspectiva democrática de trabalho e com a possibilidade de concretização de uma escola com projetos diferenciados e inovadores. A atuação do coordenador pedagógico no interior dessas escolas foi fruto de uma concepção progressista de educação em que uma nova forma de gestão escolar e do processo ensino-aprendizagem foi colocada em prática. O papel dos coordenadores nessas escolas não tinha relação com a centralização burocrática e com a hierarquização do poder defendida pelo tecnicismo (muito em voga naquele contexto histórico), pois a coordenação era eminentemente uma função de articulação pedagógica.

\footnotetext{
${ }^{5}$ A análise bibliográfico-documental apresentada neste artigo faz parte de uma pesquisa mais ampla da autora (Fernandes, 2004).
} 
Posteriormente, na década de 80, a abertura política e as eleições diretas trouxeram novos ânimos à sociedade. Houve a intensificação da atividade sindical, bem como das reivindicações por uma escola mais justa e democrática. Nessa mesma década, a sociedade conheceu um processo de mobilização popular e uma grande valorização da educação, como forma de superação da dominação política. Nesse sentido, as políticas voltadas à educação procuraram se apresentar de maneira mais aberta e democrática, oferecendo novas possibilidades de organização e gestão escolar.

Como resultado dessas novas políticas, podemos citar a implantação do Ciclo Básico (CB) ocorrida durante o governo Montoro ${ }^{6}$. O Ciclo Básico foi uma medida inovadora que teve como objetivo reduzir as elevadas taxas de retenção escolar ao final da antiga $1^{\mathrm{a}}$ série do $1^{\mathrm{o}}$ grau. Com caráter de transformação, o Ciclo Básico veio articulado a um conjunto de outras medidas que tiveram como propósito dar sustentação para a efetivação da reforma proposta (Cunha, 1995; Christov, 2001; Oliveira, 2003). Uma das medidas articuladas para a implantação do CB foi a criação da função de professor coordenador pedagógico: "Na mesma direção de priorizar o ciclo básico, foi criada a figura do coordenador, a ser eleito pelos professores dessas classes. A eleição seria anual, à época do planejamento escolar, e deveria ser referendada pelo conselho de escola" (Cunha, 1995, p. 215). Tal proposta pode ser interpretada como um indicativo da preocupação com a democratização das relações de trabalho e com o amparo pedagógico aos professores. Pelo fato de o CB ser uma grande mudança, houve a necessidade do acompanhamento dos docentes por outro professor, o que demonstrava uma relativa crença no papel do professor como sujeito e como parceiro no âmbito do cotidiano escolar.

Há registros também de que a função de coordenação pedagógica foi estendida para outras escolas da rede estadual paulista na década de 80 , porém sempre visando à implantação de projetos específicos da Secretaria da Educação, como foi o caso do Projeto Noturno (Almeida, 1998). Este projeto foi executado em 152 escolas estaduais durante 1984 e 1985 e teve por objetivo melhorar o processo de ensino-aprendizagem dos alunos do noturno por meio da elaboração de propostas de melhorias específicas para cada unidade escolar. No Projeto Noturno, a coordenação pedagógica também foi exercida por um professor eleito entre os seus pares e tinha como atribuições organizar as reuniões pedagógicas e acompanhar o desenvolvimento de

\footnotetext{
${ }^{6}$ O governo de André Franco Montoro, considerado progressista e democrático, é lembrado ainda hoje pelos professores da rede estadual. As alterações no plano de carreira e um novo Estatuto do Magistério, que eram reivindicações dos professores desde o final da década de 70, foram atendidas durante sua administração.
} 
projetos. Além do Projeto Noturno e do CB, houve também, nessa mesma década, a presença da coordenação pedagógica nos Centros Específicos de Formação e Aperfeiçoamento do Magistério (CEFAMs).

No início da década de 90, ocorreu a implantação de um novo projeto de inovação pedagógica nas escolas estaduais, o Projeto Escola Padrão. Com recursos advindos de um convênio com o Banco Mundial, a Secretaria de Educação estabeleceu algumas unidades escolares para trabalharem em regime diferenciado, as quais puderam desfrutar de maiores benefícios em relação às demais escolas estaduais. Entre os benefícios estavam: maior valorização salarial, regime de dedicação exclusiva dos professores, utilização de recursos materiais diferenciados (bibliotecas equipadas, videotecas, kits tecnológicos, laboratórios portáteis etc.), maior autonomia da direção, elaboração de um plano de gestão específico, autonomia do conselho escolar e a presença da coordenação pedagógica. Nessas escolas, a coordenação pedagógica foi formada pela coordenação geral (coordenação do diurno e coordenação do noturno) e pela coordenação de áreas ou matérias afins ${ }^{7}$, as quais eram responsáveis pela articulação pedagógica e pela efetiva implantação do projeto políticopedagógico no interior das escolas.

A partir da análise bibliográfico-documental, podemos apontar que a função de PCP esteve presente em momentos anteriores de inovação pedagógica, porém há que se ressaltar que o olhar sobre a função não foi o mesmo em todas as experiências encontradas. Podemos afirmar que o exercício da função em contextos progressistas, como os apresentados nas décadas de 60 e 80, assentava-se em uma concepção de professor-sujeito, capaz de constituir sua profissionalidade docente. Diferentemente, o contexto das reformas neoliberais (re) cria a função com o olhar centrado no papel do professor como objeto, a quem cabe a regulação pelas formas burocráticas de controle e de tarefas determinadas externamente. Dessa forma, a função pode ter sido necessária nas atuais reformas da Secretaria de Educação como uma alavanca para que as propostas presentes na "Escola de Cara Nova" saíssem a contento. Ao PCP coube o controle e a implantação das reformas educacionais no âmbito escolar, numa clara proximidade com os aspectos tecnicistas da educação, o que se constituiu em uma armadilha neoliberal ao processo de profissionalidade docente e de profissionalização das escolas públicas.

\footnotetext{
${ }^{7}$ A coordenação de área apresentava semelhanças com o trabalho realizado nos Ginásios Vocacionais em que a função também era desempenhada por um professor experiente que coordenava seus colegas sem se desvincular da sala de aula.
} 
A análise bibliográfico-documental nos ofereceu elementos importantes para configurar o contexto político de criação da função. Entretanto, um questionamento ainda precisava ser respondido: quais as condições de profissionalidade docente presentes no trabalho daqueles que passaram a desempenhar a função de PCP no bojo das reformas educacionais recentes? Para responder tal pergunta e com o objetivo de nos aproximarmos, por meio da literatura específica, do cotidiano vivenciado nas escolas, optamos por analisar pesquisas que haviam sido realizadas e que abordavam o tema em questão. A revisão das pesquisas ${ }^{8}$ nos apontou dificuldades vividas pelos PCPs que se constituíram em obstáculos decisivos para a profissionalidade e para a realização satisfatória do trabalho na função.

Um primeiro aspecto presente no trabalho cotidiano dos professores coordenadores pedagógicos e bastante explorado pelas pesquisas foi a presença constante do desvio de função (Dias-da-Silva, 2002; Christov, 2001; Clementi, 2001). Muitas atividades relatadas que eram realizadas pelos PCPs no dia a dia das escolas não faziam parte do rol de atribuições legais da função e, portanto, poderiam ser realizadas por outros sujeitos presentes na estrutura escolar, liberando o coordenador para atividades especificamente pedagógicas. A análise das pesquisas, notadamente aquelas de natureza empírica, nos permitiu verificar que em muitas escolas os PCPs realizavam atividades que lhes eram "empurradas", como, por exemplo, o cumprimento de tarefas administrativas, burocráticas e organizacionais que cabiam ao diretor, secretário de escola, inspetor de alunos, servente etc.

Uma decorrência direta do desvio de função que pudemos verificar foi a ausência de identidade e de espaço específico de atuação do PCP (Clementi, 2001; Mate, 1998; Christov, 2001; Dias-da-Silva; Lourencetti, 2002). Por se tratar de figura relativamente nova no dia a dia das escolas, os ocupantes da função se deparavam com disputas de poder e de território, pois, de certa forma, a chegada dos mesmos às escolas contribuiu para a quebra de uma rígida hierarquia organizacional que historicamente esteve presente nas unidades escolares e que garantia a centralização do poder nas mãos dos diretores.

A dificuldade para definir um território próprio para o trabalho do PCP e a falta de uma identidade clara para a função foi sendo agravada pelo isolamento dos professores em relação a

\footnotetext{
${ }^{8}$ Foram analisadas quatro teses de doutorado, seis artigos derivados de pesquisas realizadas por docentes de universidades paulistas, três artigos oriundos de teses ou dissertações e ainda três artigos provenientes de pesquisas que estavam em andamento. $\mathrm{O}$ corpus de análise foi formado por pesquisas centradas no trabalho do PCP e, em alguns casos, no trabalho, na análise da escola e, de forma indireta, no trabalho da função.
} 
outros colegas que realizavam o mesmo trabalho em outras unidades escolares (Garrido, 2000). Muitas vezes sozinho e sem espaços favoráveis para a troca de ideias com outros companheiros, o PCP apresentava um cotidiano de trabalho atropelado pelo rolo compressor da insegurança, da incerteza e da burocratização.

$\mathrm{O}$ isolamento dos professores coordenadores pedagógicos dificultava a superação de algumas dificuldades que, de acordo com as pesquisas, eram quase generalizadas entre os ocupantes da função, principalmente aquelas que se relacionavam à formação pedagógica. Se, por um lado, a não exigência da formação pedagógica favoreceu a democratização do acesso à função, por outro, permitiu que muitos docentes assumissem a difícil tarefa sem ter um claro entendimento de didática, currículo, legislação ou gestão escolar. Esse aspecto abordado por Clementi (2001), Christov (2001) e Placco (2002) deixou claro que a formação do PCP teve interferência direta no trabalho cotidiano, não tendo contribuído para uma atuação consciente e intencional no desempenho da função. As pesquisas nos levaram a concluir que nem sempre o bom professor de Matemática, Geografia ou Ciências apresentava competência ou repertório profissional para o bom desempenho do trabalho de coordenação pedagógica.

A fragilidade na formação e as dificuldades que dela decorreram para uma atuação consciente na função foram levando o PCP à realização de trabalhos relacionados à veiculação, imposição e defesa de projetos da Secretaria Estadual de Educação que, muitas vezes, desconsideravam a participação e o saber docente. Podemos afirmar que, ao agir de tal forma, os PCPs se aproximavam de uma atuação gerencial, e a eles cabia controlar as reformas educacionais, numa clara proximidade com os aspectos tecnicistas da educação (Guilherme 2002).

A imposição de mudanças e o julgamento do trabalho realizado pelos docentes também tiveram relação com os "traços" que os professores coordenadores demonstraram em sua postura, o que Clementi (2001) identificou como "vícios". Muitas vezes, esses traços estavam relacionados à concepção tecnicista de professor-executor, que, portanto, precisava ser conduzido e julgado por alguém superior a ele na rede hierárquica da escola, frequentemente de forma autoritária e impositiva.

Os estudos e pesquisas também nos levaram a afirmar que há uma nuclearidade da função de PCP na promoção e no desenvolvimento de trabalhos coletivos nas escolas. Também foi decisivo o reconhecimento de que não há nas escolas públicas uma tradição na formação de 
grupos de estudos e de reflexão e menos ainda na tomada de decisões democráticas. Nesse sentido, as pesquisas indicaram que era necessário muita habilidade do coordenador para estabelecer vínculos com os professores, ganhar a confiança do grupo e propor mudanças (Souza, 2001). Trabalhar em grupo também envolvia diferentes expectativas em relação às possibilidades de mudança na atuação do professor, o que de acordo com Placco (2002) precisava ser considerado pelo PCP em seu trabalho nas escolas.

Segundo as pesquisas, o cotidiano do PCP e sua relação com o coletivo eram marcados também pelas dificuldades encontradas pelos coordenadores para organizar e direcionar os encontros com os professores acarretando, em algumas escolas, a transformação das horas de trabalho pedagógico coletivo (HTPC) em meras exigências burocráticas, como afirma Torres (2001) ao argumentar que de "palco de negociações" as reuniões se transformavam em "palcos de encenações".

Em síntese, as pesquisas recentes nos ofereceram elementos decisivos para identificar dificuldades encontradas nas escolas no que se referia ao trabalho do PCP. Elas foram fundamentais para nos aproximar do contexto de trabalho da função e para permitir o reconhecimento das implicações que as decisões macroestruturais provocaram no universo microestrutural das escolas, uma vez que as dificuldades apontadas foram componentes decisivos para fragilizar a constituição da profissionalidade docente entre os ocupantes da função, principalmente se considerarmos a questão da deficiência na formação dos PCPs que foi apresentada pelas pesquisas. A não exigência da formação pedagógica específica e da longa experiência de trabalho docente, associadas às condições de trabalho adversas, trouxeram implicações consideráveis para a realização satisfatória do trabalho cotidiano.

Nesse contexto adverso, é decisivo salientar que a constituição da profissionalidade docente foi sendo fortemente influenciada pelo neoliberalismo e pelas reformas educacionais que desfavoreceram a formação profissional em detrimento de uma maior valorização das "experiências" de trabalho e de uma concepção individualizante de sucesso nas escolas, em que as palavras-chave para a atuação do professor passaram a ser empreendedorismo e polivalência (Kuenzer, 2002).

Desta forma, o contexto de criação da função de PCP, no bojo das reformas educacionais dos anos 90, foi marcado pela institucionalização de um trabalho que não foi acompanhado da preocupação da Secretaria de Educação com a formação profissional, com as condições 
necessárias para a realização de um trabalho coletivo e com o desenvolvimento profissional do professor como sujeito do processo educacional. Assim, o sucesso do trabalho do PCP nas unidades escolares passou a ser quase exclusivamente uma responsabilidade individual, cabendo ao docente empreendedorismo, criatividade, confiança e disposição para a realização satisfatória da função, o que vai de encontro com a afirmação de Cunha (1999) sobre a profissionalidade docente:

A individualidade é valor intrínseco à competitividade, esteio da nova ordem. A escola e o professor passam a ser mercadorias, postas na bolsa de valores, em que vencerão os mais preparados, sempre vistos individualmente. Não é preciso lembrar que essa lógica é perversa porque sempre reforçará os mais privilegiados, que têm melhores condições de escolha. Além disso, uma tal lógica compromete a concepção de igualdade, esteio do estado democrático e, o que é pior, inviabiliza a noção verdadeira de solidariedade e de projeto coletivo. (p. 154)

É necessário considerar ainda que, além da falta da formação pedagógica, o tempo de experiência docente que passou a ser exigido para a ocupação da função também contribuiu para fragilizar a profissionalidade do professor coordenador pedagógico. Apesar de ter sido positiva a possibilidade de que o PCP fosse um parceiro dos demais docentes na articulação pedagógica das escolas, nossa análise nos permitiu inferir que nem sempre esse fato se constituía em indicador de êxito no trabalho cotidiano. $\mathrm{O}$ docente com três anos de experiência, tempo mínimo exigido pela legislação para o acesso à função, situava-se, de acordo com os ciclos vitais dos professores (Huberman, 1992), na fase inicial da carreira, fase identificada como de sobrevivência e descobrimento que se traduz no "choque com a realidade" e na diferença entre os ideais do professor e os aspectos reais das escolas. Esta primeira fase do trabalho docente, segundo Huberman, é normalmente marcada por conflitos, angústias e insegurança diante do novo e complexo cenário educacional. Neste sentido, afirmamos ser pequena a probabilidade de que um professor com apenas três anos de experiência profissional apresente um know-how pedagógico para conduzir com suficiente clareza um grupo de professores e oferecer-lhes segurança, apoio e até mesmo aconselhamento diante dos embates cotidianos.

Em nossa investigação bibliográfico-documental, encontramos evidências de que em outros momentos, mesmo em épocas mais remotas, alguns professores já haviam atuado no acompanhamento das práticas pedagógicas nas escolas, como foi o caso dos inspetores escolares que realizaram seu trabalho no Estado de São Paulo a partir da década de 1920 (Nagle, 2001; 
Mitrulis, 1993). A inspeção escolar era realizada por um professor considerado bem-sucedido que depois de ampla experiência educacional recebia a incumbência de acompanhar o trabalho realizado nas escolas. Assim, a função dos inspetores na "coordenação" das escolas advinha do "saber da experiência". Entretanto, é preciso problematizar que nesses casos o professor apenas tinha acesso à função depois de larga experiência de trabalho em sala de aula ou na gestão escolar, diferentemente do atual PCP que não precisa ter uma longa trajetória de experiência no trabalho docente. Dessa forma, a pouca experiência de trabalho docente exigida para a ocupação da função neste contexto neoliberal constituiu-se em mais um elemento que interferiu nas condições de profissionalidade docente.

A preocupação com os aspectos de formação do professor coordenador pedagógico e a constituição de sua profissionalidade nesse contexto de trabalho adverso ficou, de acordo com nossa análise, centrada no trabalho sindical, uma vez que a Apeoesp, o maior sindicato estadual dos professores, foi quem iniciou em 1996, logo depois da expansão da função, um curso de formação para os novos $\mathrm{PCPs}^{9}$ com o objetivo de auxiliá-los no reconhecimento do papel político e profissional desse trabalho. Almeida (2000) afirma que o projeto de formação concebido e desenvolvido pelo sindicato procurou articular as dimensões técnico-pedagógica e políticosindical, buscando contribuir para a constituição da identidade profissional do professor:

Esse projeto procura superar a concepção individualista de formação, centrada no professor e organizada à margem do seu desenvolvimento profissional. Para tanto, defende que a mudança da profissionalidade e o aperfeiçoamento dos professores devem ser entendidos como um modelo de desenvolvimento profissional e pessoal, evolutivo e continuado, que precisa estar referenciado nos contextos que determinam a prática. Nessa medida, o desenvolvimento dos professores passa a ser produzido num espaço mais amplo, que é a escola, o que implica enfocar todos os aspectos implicados na prática docente. (p. 5)

Com base em nossa investigação, concluímos que a presença dos professores coordenadores pedagógicos estava inserida em um contexto contraditório marcado pelo jogo sutil entre as reformas educacionais dos anos 90 e a presença de uma visão progressista de educação, herança dos anos 60 e 80 . Neste jogo entre o tecnicismo e a re-significação do papel dos

\footnotetext{
${ }^{9}$ O tema do curso foi: "Reinventando a escola: a construção da prática pedagógica coletiva". O projeto coordenado por sindicalistas e pesquisadores (Selma Garrido Pimenta, José C. Fusari, Silvia M. Manfredi e Maria Isabel de Almeida), foi uma tentativa de oferecer amparo político e pedagógico aos novos ocupantes da função por meio de encontros regionais e de publicações específicas, os chamados Cadernos de Formação.
} 
professores, é que foi sendo situada a coordenação pedagógica em São Paulo, que, tentando responder a diferentes objetivos para a função, muitas vezes contraditórios, passou a enfrentar o complexo cotidiano das escolas públicas estaduais ora aceitando as imposições, ora resistindo e criando saídas alternativas para o cotidiano escolar. Neste contexto em que o professor coordenador passou a conviver com condições de trabalho adversas, com a falta de formação específica, com a ausência de uma política de valorização do magistério e com uma sociedade em constante mudança, ele se tornou protagonista de uma função que convive com muitas dificuldades e com a fragilização evidente de sua profissionalidade.

Assim, ao concluir, não podemos deixar de registrar a necessidade de as políticas públicas elaboradas e implementadas considerarem a importância das condições de trabalho e de profissionalidade como elementos essenciais para o exercício satisfatório da função de professor coordenador pedagógico. Desde a necessidade de uma estrutura física nas escolas que acolha o PCP e favoreça os encontros coletivos (pois em muitos lugares não há nem mesmo uma sala para o professor coordenador trabalhar) até as possibilidades de estudo e formação continuada, sem falar na remuneração e na redução da rotatividade docente, são muitas as exigências para evitar que a precariedade das condições de trabalho anulem a importância da função, produzindo um efeito perverso que pode transformá-la em uma armadilha, em que o PCP passe de sujeito a objeto, se alinhando às forças neoliberais que o querem sob controle num estado de maior alienação (Cunha, 1999) fragilizando, dessa forma, o importante papel de articulação pedagógica que o ideário progressista atribuiu ao professor.

\section{REFERÊNCIAS BIBLIOGRÁFICAS}

ALMEIDA, L. R. O Coordenador pedagógico ante o desafio de articular e mobilizar a equipe escolar para tecer o projeto pedagógico. In: GUIMARÃES, A. A. et al. O Coordenador pedagógico e a educação continuada. São Paulo: Loyola, 1998. p. 21-22.

ALMEIDA, M. I. Desenvolvimento profissional docente: uma atribuição que também é do sindicato. In: REUNIÃO ANUAL DA ASSOCIAÇÃO NACIONAL DE PÓS-GRADUAÇÃO E PESQUISA EM EDUCAÇÃO, 23., 2000, Caxambu. Anais...Caxambu: ANPED, 2000.

Disponível em: <http://www.anped.org.br/inicio>. Acesso em: 06 set. 2004.

CHRISTOV, L. H. S. Sabedorias do coordenador pedagógico: enredos do interpessoal e de (con) ciências na escola. 2001. 162 f. Tese (Doutorado em Psicologia da Educação) - Pontifícia Universidade Católica, São Paulo. 
CLEMENTI, N. A Voz dos outros e a nossa voz. In: ALMEIDA, L. R.; PLACCO, V. M. N. S. (Org.). O Coordenador pedagógico e o espaço da mudança. São Paulo: Loyola, 2001. p. 53-66.

CUNHA, L. A. Educação, estado e democracia no Brasil. São Paulo: Cortez, 1995.

CUNHA, M. I. Profissionalização docente: contradições e perspectivas. In: VEIGA, I. P. A.; CUNHA, M. I. (Org.). Desmistificando a profissionalização do magistério. Campinas: Papirus, 1999. p. 127-147.

DIAS-DA-SILVA, M. H. G. F. Prefácio. In: REALI, A. M. M. R.; MIZUKAMI, M. G. N. (Org.). Formação de professores: práticas pedagógicas e escola. São Carlos: EDUFSCar, 2002. p. 21-25.

DIAS-DA-SILVA, M. H. G. F.; LOURENCETTI. G. C. A Voz dos professores e algumas reformas educacionais nas séries finais do ensino fundamental: desenvolvimento ou impasse? In: SAMPAIO, M. M. F. O Cotidiano escolar face às políticas educacionais. Araraquara: JM, 2002. p. 21-43.

FERNANDES, M. J. S. Problematizando o trabalho do professor coordenador pedagógico nas escolas públicas estaduais paulistas. 2004. 113 f. Dissertação (Mestrado em Educação Escolar) Faculdade de Ciências e Letras, Universidade Estadual Paulista, Araraquara.

FUSARI, J. C. Formação contínua de educadores. 1997. 200 f. Tese (Doutorado em Educação) Faculdade de Educação, Universidade de São Paulo, São Paulo.

GARCIA, M. Coordenação pedagógica: ação, interação, trans-formação. 1995. 134 f.

Dissertação (Mestrado em Educação: Supervisão e Currículo) - Pontifícia Universidade Católica, São Paulo.

GARRIDO, E. Espaço de formação continuada para o professor coordenador. In: BRUNO, E. B. G.; ALMEIDA, L. R.; CHRISTOV, L. H. S. (Org.). O Coordenador pedagógico e a formação docente. São Paulo: Loyola, 2000. p. 9-16.

GUILHERME, C. C. F. A Progressão continuada e a inteligência dos professores. $2002.143 \mathrm{f}$. Tese (Doutorado em educação) - Faculdade de Ciências e Letras, Universidade Estadual Paulista, Araraquara.

HUBERMAN, M. O Ciclo de vida profissional dos professores. In: NÓVOA, A. Vidas de professores. Porto: Porto, 1992.

KUENZER, A. Z. O Trabalho pedagógico: da fragmentação à unitariedade possível. In: FERREIRA, N. S. C.; AGUIAR, M. A. S. (Org.). Para onde vão a orientação e a supervisão educacional? Campinas: Papirus, 2002. p. 47-78. 
MARIN, A. J.; GUARNIEIRI, M. R. Escola Fundamental, ações de inovação e desenvolvimento profissional de professoras: focalizando as salas-ambiente. In: SAMPAIO, M. M. F. O Cotidiano escolar face às políticas educacionais. Araraquara: JM, 2002. p. 47-65.

MATE, C. H. Qual a identidade do professor coordenador pedagógico. In: GUIMARÃES, A. A. et al. O Coordenador pedagógico e a educação continuada. São Paulo: Loyola, 1998. p. 17-20.

MITRULIS, E. Os Últimos baluartes - uma contribuição ao estudo da escola primária: as práticas de inspeção escolar e de supervisão pedagógica. 1993. 213 f. Tese (Doutorado em educação) - Faculdade de Educação, Universidade de São Paulo, São Paulo.

NAGLE, J. Educação e sociedade na primeira república. 2. ed. Rio de Janeiro: DP\&A, 2001.

OLIVEIRA, T. F. M. Escola, cultura do ideal e do amoldamento. São Paulo: Iglu, 2003.

PLACCO, V. M. N. S. Formação de professores: o espaço de atuação do coordenador pedagógico-educacional. In: FERREIRA, N. S. C.; AGUIAR, M. A. S. (Org.). Para onde vão a orientação e supervisão educacional? Campinas: Papirus, 2002. p. 95-106.

SAMPAIO, M. M. (Org.). O Cotidiano escolar face às políticas educacionais. Araraquara: JM, 2002.

SILVA JR., C. A. Supervisão, currículo e avaliação. In: FERREIRA, N. S. C. (Org.). Supervisão educacional para uma escola de qualidade. 3. ed. São Paulo: Cortez, 2002. p. 223-233.

SOUZA, V. L. T. O Coordenador pedagógico e a constituição do grupo de professores. In: ALMEIDA, L. R.; PLACCO, V. M. N. S. (Org.). O Coordenador pedagógico e o espaço da mudança. São Paulo: Loyola, 2001. p. 27-34.

TAMBERLINI, A. R. M. B. Os Ginásios vocacionais: a dimensão política de um projeto pedagógico transformador. São Paulo: Annablume, 2001.

TORRES, S. R. Reuniões pedagógicas: espaço de encontro entre coordenadores e professores ou exigência burocrática? In: ALMEIDA, L. R.; PLACCO, V. M. N. S. O Coordenador pedagógico e o espaço da mudança. São Paulo: Loyola, 2001. p. 45-51.

Recebido em: outubro 2009

Aprovado para publicação em: novembro 2009 